first four or five hours of its flight. Two of the occupants were unwell and in dropping rapidly through cloud, the collection of ice on the gondola, together with that falling on it from the lower part cf the balloon structure itself, and other chafing actions, eventually parted the gondola from the balloon. The chief object of the flights, organised by the Society for Aviation and Chemical Warfare, was to investigate cosmic rays and it has been said that thirty instruments for various purposes were being carried. The balloon expanded had a diameter of $115 \mathrm{ft}$. and the whole weighed 2 tons. The metal parts were of rustless steel. The lowest pressure record of $50 \mathrm{~mm}$. $(61,000 \mathrm{ft}$. $)$ for a balloon rests at present with the stratostat U.S.S.R. piloted by M. Prokofiev last September.

Photographs and Early Maps of the Fenland of East Anglia

In the Art Gallery of Messrs. W. Heffer and Sons, Ltd., Cambridge, there is an exhibition of ancient maps of the Fenland and of recent aerial photography of the same region. This exhibition, which will be open until February 12, directs attention to the activities of the organising body, the Fenland Research Committee, which was founded under the presidency of Prof. A. C. Seward in 1932, for promoting the intensive investigation of the complex history of the Fenland basin. The members represent the interests of archæological, botanical, geological and historical science, co-operating closely in attacking the very complex problems of the developmental history of the Fenland basin. Co-ordinated excavations have already been made and a number of publications have appeared. One extremely important side of the work of the Committee is the aerial photography of the entire region. This reveals on the silt area of the fens beside the Wash a hitherto unsuspected density of remains of the Romano. British occupation and of later times. Field systems, dwellings, river-beds, droves and creeks are visible in great profusion and clarity, and the examination, interpretation and mapping of these remains will be a major activity of the Committee for some time to come. The preparation of suitable field maps for use in this task is a heavy charge on the Committee and the exhibition is intended to stimulate public assistance to the provision of part or all of the sum of $£ 500$ required.

\section{Beam Wireless Communication with China}

ON February 3 a new Marconi beam wireless station was opened at Chenju, near Shanghai, to give direct radio communication with Great Britain, and it is anticipated that within the next year Shanghai will be in telephonic communication with London. This will add yet another link to the already widespread ramifications of the international radio telephone service available from London. In announcing the opening of the now station, the Times recalled the fact that the first wireless station in China was erected by that journal at Wei-hai-wei in 1904 in order to receive dispatches during the Russo. Japanese war from its correspondents on board a steamer specially chartered for the purpose. The Marconi Co. later undertook the establishment of communication for the Chinese Government, and the recent extension referred to above is due to the enterprise of the Ministry of Communications. The whole of the technical material used for the Chenju station was purchased in Great Britain with funds from the British Boxer indemnity, and Chinese engineers have co-operated most effectively in the installation.

\section{Electric Discharge Lamps}

Some interesting characteristics of the new electric discharge lamps were described and demonstrated in a lecture given before the North-West Area Section of the Illuminating Engineering Society at Manchester on January 30 by Mr. H. R. Ruff, of the Research Department of the British Thomson Houston Co., at Rugby. Mr. Ruff showed that highly-coloured wall papers are completely robbed of their colour by a form of lamp using sodium vapour, appearing as though executed only in black, white and grey. On the other hand, an electric discharge lamp using mercury vapour was shown to contain strong yellow, green and blue elementswith the result that coloured papers show up quite well by this light. Numerous installations of these lamps are being made in streets throughout Great Britain, and they are also proving to have interesting possibilities for use in factories. A certain amount of care is, however, necessary when applying them to processes with revolving machinery, owing to the formation of stroboscobic effects, by which wheels appear to be turning in a contrary direction. These lamps provide about 16,000 lumens for a consump. tion of 400 watts and can be adapted to ordinary supply circuits using either alternating or direct currents, although the former is more convenient. The efficiency is $2 \frac{1}{2}-3$ times that of a filament lamp. A new form of vacuum lamp containing mercury which emits a moderate amount of ultra-violet light and is thus useful from the hygienic point of view was also shown.

\section{Constitution of the Upper Atmosphere}

Present conceptions of the physical and chemical constitution of the upper atmosphere were summarised in a most entertaining way by Dr. G. C. Simpson in the twenty-fourth Bedson lecture delivered at Armstrong College, Newcastle-upon-Tyne, on February 2. Dr. Simpson dealt first with the thickness of the troposphere over the earth's surface, and the temperature distribution within it, and throughout the stratosphere, including the discoveries of Lindemann and Dobson since 1920 from observations of meteors, also ozone concentration and distribution relative to (surface) atmospheric pressure. The evidence of sound wave and wireless wave reflections was then reviewed, and finally the evidence from auroral observations on the influence of sunlight, and on the composition of the atmosphere. Clouds in the stratosphere, and the dissociation of oxygen and nitrogen molecules at $100 \mathrm{~km}$, and above were 
all touched upon. Throughout his lecture, Dr. Simpson stressed the uncertainty of prophecy in these matters, but his exception of weather forecasting caused amusement. Most of the learned societies of the district were represented in the audience, which was highly appreciative of the visit.

\section{Neon Signs}

The discharge tubes used for advertising are a development of the old Geissler and Crookes tubes in which various beautiful effects were produced when evacuated tubes filled with certain gases were excited by an induction coil. In the January Engineering Supplement to the Siemens Magazine, there is an interesting article on the construction and the physical theory of commercial discharge tubes by E. A. Beavis. Forty years ago, the gases used were mostly nitrogen and carbon dioxide, and these required continual replenishing. It was only when the rare gases, argon, neon, helium, etc., were experimented with that it was found possible to obtain a reasonably permanent luminous discharge. These gases are not subject to absorption to anything like the same extent as the commoner gases. Neon at a suitable pressure gives more visible light and has a lower electrical resistance than the other permanent gases and hence a greater length of tubing can be operated for a given voltage. Neon has a cheerful red glow, argon gives a faint lavender colour and has little luminosity, and helium has a whitish glow. Combinations of various gases and vapours with neon and the use of coloured glass tubes have enabled many striking and pleasing coloured effects to be obtained. The positive column extending to the anode forms the main region of luminosity in the tube. By mixing traces of impurity in the gas, it is possible to obtain narrow cords of light which move within the tube and give rise to the type of discharge known as the 'ripple neon'. Sometimes also the column of light splits up into rows of coloured discs which often rotate round the axis of the tube. These effects are known as 'striations'. Alternating current is used for operating commercial tubes. As the voltage absorbed under running conditions is about 200 volts per foot of tube, it is usually divided up into a number of sections each supplied by a separate transformer.

\section{Banting Research Foundation, Toronto}

THIs foundation arose out of the desire to com. memorate the discovery of the active principle of the islets of the pancreas by Dr. F. G. Banting in 1921-22, and has received wide financial support in Canada. It has now been in active operation for six and a half years, though in the first two years the full capital sum was not available and the number of grants made were few. The capital sum now amounts to about 700,000 dollars and the number of individual grantees has steadily increased. The total number of grants made during the period is $\mathbf{9 2}$. These have been distributed to 63 workers in the following universities: Alberta 4, Saskatchewan 2, Dalhousie 8, Queen's 2, Western Ontario 2, Manitoba 16, McGill 26, Toronto 30 and 2 non-university.
Some fifty papers have already appeared in scientific publications, while a further fifteen are in press or ready for publication. Several pieces of work are not as yet complete. In accordance with its charter, the Foundation also aids in the support of the Department of Medical Research, University of Toronto (Dr. F. G. Banting) and from this source numerous papers on silicosis, the action of vitamins and other topics have appeared. During the past year twenty workers received grants from the fund. The Foundation, which is the only one in Canada giving support to medical research, has proved a valuable aid and stimulus to such research in that country. The world economic depression has increased the demands upon the Foundation, the trustees of which would welcome a larger revenue. Correspondence should be addressed to the Banting Research Foundation, Toronto, Canada.

\section{Reptile Skins in Commerce}

A FEw years ago the use of the skins of reptiles in the manufacture of shoes was regarded as a whim of the moment, but now the view is strongly held by the leather trade and by technical experts in the industry that the skins are established as a raw material for leather production on as permanent a basis as goat, calf and sheep skins. This is the view expressed by the sub-committee appointed by the Imperial Institute Advisory Committee on Hides and Skins (Bull. Imp. Inst., 31, No. 2, 160 ; 1933). The change in outlook has taken place since 1926, when reptile skins were employed only in the making of luxury articles; now they are used for the massproduction types of shoes, as well as for bag and fancy leathers. Some of the advantages of reptile leather are that it is hard-wearing, stronger than sheep, goat or even calf skins; it shows great variety of pattern and design; and it takes colour readily. But the demand has been telling upon reptile populations in various tropical countries. In 1932, India exported $2 \frac{1}{2}$ million reptile skins; in 1931, more than two million came from the Dutch East Indies; and serious depletion has occurred in the stock of the North American alligator, the edible terrapins of the United States, and the green turtle, the last being valued as food. An exhibition of reptile skins and their products will be opened at the Imperial Institute on February 12 at noon by Lieut.-Col. J. Colville, Parliamentary Secretary to the Department of Over. seas 'Trade.

\section{Eton College Natural History Society}

IT is encouraging to find that in the public schools of Great Britain there is no sign of declining interest in field studies. The expeditions held on holidays and half-holidays by the Eton College Society are excellent as introductions to natural history, and may lead to the more individual interest which is revealed in the lists of records, of lectures, and of museum preparations mentioned in the annual report for 1932-33. The report is enlivened by photographs taken by the members, and a list of Lepidoptera from the Eton district, by Brigadier-General B. H. Cooke, should be useful as a check-list for youthful collectors. 